Gendreau, P.L., \& Lewis, M.H. (2005). Social deprivation, social-emotional behavior, and the plasticity of dopamine function. In D.M. Stoff \& E.J. Susman (Eds.), Developmental psychobiology of aggression (pp. 43-68). Cambridge, MA: Cambridge University Press.

\title{
Social Deprivation, Social-Emotional Behavior, and the Plasticity of Dopamine Function
}

\author{
Paul L. Gendreau \\ University of Montréal \\ Mark H. Lewis \\ University of Florida
}

\section{BRAIN PLASTICITY AND SOCIAL DEVELOPMENT}

The notion of plasticity in relation to biological and behavioral development is not a new one. Even when very little was known about brain structure and function and long before the advent of modern molecular and neuroanatomical techniques, scientists recognized that the brain had the capacity to adapt and change in response to environmental input. Already in 1892, William James stressed the importance of brain plasticity in the organization of habits:

Plasticity, then, in the wide sense of the word, means the possession of a structure weak enough to yield to an influence, but strong enough not to yield all at once. Each relatively stable phase of equilibrium in such a structure is marked by what we call a new set of habits. Organic matter, especially nervous tissue, seems endowed with a very extraordinary degree of plasticity of this sort; so that we may without hesitation lay down as our first proposition the following: that the phenomena of habit in living beings are due to plasticity of the organic materials of which their bodies are composed. (p. 2, italic original (James, 1892)

James's intuition was confirmed in the 196os when a group of scientists provided the first empirical evidence of environmentally induced alterations in brain chemistry and structure (Diamond, Krech, \& Rozenzweig, 1964; Krech, Rozenzweig, \& Bennett, 1960; Rozenzweig, Krech, Bennett, \& Diamond, 1962). Importantly, it was shown that these neurobiological alterations were associated with enhanced behavioral and particularly cognitive functions. In the past four decades, an increasing body of evidence has recognized further the crucial and time-dependent influence of the environment in shaping the developing brain. Well known is the seminal work of Wiesel and Hubel, who demonstrated that early monocular deprivation in kittens produced persistent functional alterations in neurons of the visual cortex (Wiesel \& Hubel, 1965). This finding led to the important finding that specific visual input had to be presented during a precise 
window of time for vision to develop normally (Hubel \& Wiesel, 1970). The notion of critical period for the establishment of normal brain and behavior functions has received a great deal of attention among developmental neurobiologists and behavioral scientists (for a review see Greenough, Black, \& Wallace, 1987, and Bornstein, 1989).

With respect to social behavior and the importance of the environment in shaping its development, several important issues are still to be answered. For instance, what environmental factors are most capable of altering social behavior? Are there sensitive periods for the establishment of social behavioral patterns? What altered neurobiological functions are associated with these environmentally induced changes in social behavior? To what extent are the brain structures involved in the development and expression of social behavior malleable?

A first attempt to answer these questions was initiated by the late Robert Cairns at the University of North Carolina at Chapel Hill. Approximately 25 years ago, Cairns set in motion a program of selective breeding of ICR mice based on the animals' propensity to exhibit either high or low levels of aggression following isolation housing (Cairns, MacCombie, \& Hood, 1983). Mice were singly caged from 21 days of age to approximately 4550 days, as this specific period of ontogeny and this particular length of isolation (sensitive period) were shown to produce the highest levels of aggression (Cairns, Hood, \& Midlam, 1985). Hence, by altering the social environment during a restricted window of time, two lines of mice that differed markedly in behavioral reactivity were produced: one line of animals that promptly and ferociously attacked and a second line that exhibited high levels of freezing and nonagonistic social approach (for a review see Cairns, Gariépy, \& Hood, 1990 or Gariépy, 1995).

In the early 1990s, our research group began to investigate the neurobiological bases of these line differences in isolation-induced social reactivity. Based on a previous study in monkeys that showed enhanced behavioral response to apomorphine in animals that had been socially deprived (Lewis, Gluck, Beauchamp, Keresztury, \& Mailman, 1990), we examined the effects of the full-efficacy $D_{1}$ receptor dopamine agonist dihydrexidine on the social behavior of these high and low aggressive mice (Lewis, Gariépy, Gendreau, Nichols, \& Mailman, 1994). Whereas other ligands (e.g., chlordiazepoxide, phenelzine) failed (Tancer, Gariépy, Mayleben, Petitto, \& Lewis, 1992) dihydrexidine drastically altered the expression of social reactivity in both strains. In the high aggressive line, the number of attacks was dose-dependently reduced. In fact, it was almost nonexistent at the highest dose tested (10 $\mathrm{mg} / \mathrm{kg}$ ). In the low aggressive line, it was the frequency of nonagonistic approaches that followed a similar pattern. But above all, the most impressive effect was the large increase in social-emotional reactivity (e.g., escape, startle, kicking, upright defensive posture) that was observed in response to what would be normally 
mild and nonthreatening social stimulation. By a simple administration of a dopamine agonist, we were basically able to wipe out the effects of 20 generations of selective breeding on isolation-induced aggression and to transform aggressive mice - and to a lesser extent docile mice - into extremely reactive/fearful animals (Gariépy, Lewis, \& Cairns, 1996).

These results generated a set of experiments examining in more detail the role of dopamine and its specific receptors in the mediation of isolationinduced behavioral reactivity. Research was conducted not only in these selectively bred mice (e.g., Gariépy, Gendreau, Mailman, Tancer, \& Lewis, 1995; Gariépy, Gendreau, Cairns, \& Lewis, 1998) but also in other strains of mice in order to assess the generality of our findings (e.g., Gendreau, Gariépy, Petitto, \& Lewis, 1997a; Gendreau, Petitto, Gariépy, \& Lewis, 1998; Gendreau, Petitto, Petrova, Gariépy, \& Lewis, 2000). Briefly, our findings indicated that dopamine played an important role in the mediation of specific forms of social reactivity induced by prolonged social deprivation and suggested that D1-like and D2-like dopamine receptors were differentially involved in the expression of this reactivity.

An impressive amount of work on the effects of isolation housing as well as maternal separation on dopamine function and behavioral development in rats has been coming from Trevor Robbins' laboratory in England (e.g., Hall, Wilkinson, Humby, \& Robbins, 1999; Jones, Marsden, \& Robbins, 1990; Matthews, Dalley, Matthews, Tsai, \& Robbins, 2001). Robbins and his colleagues demonstrated the significant plasticity of dopamine function following maternal separation in young animals and social deprivation in older animals. Altogether these studies in mice and rats indicated an important role for dopamine in mediating the effects of social deprivation on subsequent behavior. Here, we summarize some of the findings related to the plasticity of dopamine function in response to both long-term social deprivation and repeated bouts of maternal separation. Furthermore, we examine how these neurobiological changes are associated with the expression of emotional, more specifically social-emotional, behavior.

\section{SOCIAL INFLUENCES ON BEHAVIORAL DEVELOPMENT:}

BRIEF HISTORICAL PERSPECTIVE

The investigation of the effects of the social environment on neurobehavioral development has relied on two major models or frameworks: the social deprivation paradigm and the early maternal separation paradigm. These two frames of reference have different but related historical starting points. Long-term social deprivation studies have been used extensively to examine the contribution of environmental factors on a variety of behavioral functions. Already in the late 19th century, this paradigm was used by both sides of the nature-nurture controversy to defend the notion 
that behavioral development was the result of maturation, independent of environmental influences; the consequence of postnatal conditioning; or - more appropriately - the product of a complex interaction between hereditary (genetic) and environmental factors (Carmichael, 1925). The effects of prolonged social isolation on behavioral development have been documented in a considerable number of species, including nonhuman primates, sheep, dog, rat, mouse, duck, chicken, fish, and even fruit fly! Almost a century ago, Craig (1914) used the social isolation paradigm to induce abnormal behavioral development in doves. Calvin Stone (1926) at Stanford University investigated the effects of social deprivation on sexual behavior in rats. Then, even before the influential studies of Harry Harlow, the effects of prolonged social deprivation in nonhuman primates had been examined (e.g., Foley, 1934; McCulloch \& Haselrud, 1939).

Parallel to these early studies of social deprivation in animals, revealing but tragic observations were being made in humans at the time of World War II. In a series of papers published in The psychoanalytic study of the child, René Spitz noted that institutionalized infants were commonly afflicted by a specific group of physical, emotional, and psychosocial impairments, a collection of symptoms referred to as the "hospitalism syndrome" (Spitz, 1945; Spitz \& Wolf, 1946). Among the symptoms reported were delayed maturation, diminished reaction to social stimulation, increased sadness, high levels of stereotyped behavior, and social withdrawal. Although several reports concerning the impact of institutional care upon child development had been published prior to these observations - reports that revealed the extremely high rates of mortality among institutionalized infants (Bakwin, 1949) - Spitz was the first to describe systematically this syndrome in infants and to offer a explanation. Based on the purest psychoanalytic tradition, Spitz suggested that this developmental abnormality was the result of a disrupted mother-infant relationship, literally the "loss of the love object." Even though this conclusion was confounded by the fact that the infants were probably more affected by the general absence of proper care rather than the absence of the mother per se, these observations initiated an important line of research on the short- and long-term consequences of early, more particularly maternal, deprivation on children's development. Around the time Spitz published his observations, a number of studies on human attachment and anxiety in relationship to maternal separation were emerging in Europe (Bowlby, 1940). Subsequently, animal studies of maternal separation were conducted in nonhuman primates (Hinde \& Spencer-Booth, 1971; Kaufman \& Rosenblum, 1967) and other mammals such as sheep, dogs, and cats (see Cairns, 1979). During the past three or four decades, studies of the effects of maternal separation upon her offspring's development have been conducted primarily in rats. This has proved to be a useful 
experimental model, as brain and behavior development is rapid in this species.

The social deprivation paradigm and the early maternal separation paradigm differ in many experimental aspects. In social deprivation studies, the animal is without any social contact for a period of time that ranges from one or a few days to several months. In addition, the onset of deprivation usually occurs once weaning is completed, at least in rodents. In nonhuman primates, social deprivation, either partial or "total," has been often conducted as soon as a few hours after birth. Isolation confinement typically prevents tactile (sometimes visual) contact and social interaction with conspecifics. Conversely, maternal separation is performed before weaning, typically within the first few days after parturition, lasts a few minutes to several hours, and is usually repeated several times. In this paradigm, the motherless pup is rarely left alone but remains with other pups in a temperature-controlled incubator. In addition - and this seems to be a key element for the observed effects the interactions between the mother and the pup are altered following reunion.

SOCIAL DEPRIVATION AND MATERNAL SEPARATION: EFFECTS ON SOCIAL-EMOTIONAL BEHAVIOR

Both maternal separation and prolonged social deprivation are known to alter significantly the expression of social-emotional reactivity in animals. Given the important distinctions both between and within each of these two paradigms, it is not surprising that different behavioral outcomes have been observed. Prolonged individual housing is recognized to produce a set of behavioral abnormalities traditionally referred to as the "social deprivation syndrome" (Goosen, 1981) or more simply "the isolation syndrome" (Hatch et al., 1965; Valzelli, 1973). One of the most constant and robust characteristics of animals that have been socially isolated is their lower threshold for exhibiting high levels of emotional reactivity to stimuli of various modalities (Bernstein \& Mason, 1962; Cairns, 1972). Such behavioral hyperreactivity is seen even in response to what would normally be mild and nonthreatening stimuli and is particularly robust when isolated animals are exposed to social stimulation (Gendreau et al., 1997a; Rodgers \& Cole, 1993). Depending on genetic/biological predisposition, social deprivation has been shown to increase aggressiveness, social avoidance, depressive symptoms, and defensive or fearlike behavior in different mammalian species, including nonhuman primates (Harlow \& Suomi, 1974; Mason \& Sponholz, 1963), dogs (Fuller \& Clark, 1966), and rodents (Cairns et al., 1985; Krsiak, 1975; Lagerspetz, Tirri, \& Lagerspetz, 1968). Isolated animals, particularly nonhuman primates, have been shown also to exhibit stereotyped behavior, learning deficits, self-injurious behavior, and 
inadequate reproductive and maternal behavior (Gluck \& Sackett, 1974; Mason \& Berkson, 1975).

Animals that have experienced repeated maternal separation early in ontogeny exhibit a behavioral syndrome in adulthood somehow different from what has been reported for animals that have been deprived of social contact after weaning. Contrary to animals that have undergone prolonged post-weaning social isolation, maternally deprived animals commonly show a higher threshold for emotional responding and blunted emotional reactivity or ahedonia, a set of symptoms that is reminiscent of depression (Sanchez, Ladd, \& Plotsky, 2001). This is associated with dysregulation of the hypothalamic-pituitary-adrenal (HPA) axis. This pattern of emotional expression and regulation is opposite to what is observed immediately after removal of the mother as pups react to maternal absence by exhibiting enhanced motor-behavioral arousal (Hofer, 1975). Adult rats that experienced early maternal separation typically show higher locomotor activity in a novel setting but only after an initial period of lower activity (Meaney, Brake, \& Gratton, 2002).

It is tempting to suggest that animals separated from their mother exhibit a behavioral syndrome that is opposite to that of animals deprived of social contact after weaning (Hall, 1998). This suggestion, however, is based on a relatively small number of findings as the majority of maternal separation studies have focused on the immediate effects rather than the long-term consequences. In addition, whereas studies on the effects of social deprivation have targeted a wide spectrum of behavioral and neurobiological functions, studies on maternal separation have mainly focused on the effects on neuroendocrine function. The significant procedural differences between the studies (e.g., strain or species, number and duration of separation bouts, age at which separation or deprivation occurs) also make the comparisons delicate. Finally, considering the possibility that early development may be characterized with more precise and more sensitive windows of vulnerability, it is not surprising that studies of maternal separation generally produce more inconsistent results than those performing the social deprivation procedure later in ontogeny.

\section{DOPAMINE FUNCTION IN SOCIALLY AND} MATERNALLY DEPRIVED ANIMALS

Since the discovery of dopamine (DA) as a neurotransmitter in the late 1950s (Blaschko, 1957; Carlsson, Lindqvist, Magnusson, \& Waldeck, 1958), much has been learned concerning its function and mode of action. Nowadays, DA is known to mediate a variety of behavioral and physiological functions and has been associated with the manifestation of psychosocial disturbances in humans (e.g., schizophrenia, drug abuse). Nevertheless, its role in mediating emotional behavior in animals has been somehow 
overlooked. This may be due to the fact that traditional animal models of emotional behavior do not allow the expression of a wide range of behaviors, do not produce a sufficient amount of novelty, or do not generate enough emotional stimulation to differentiate the contribution of DA in the expression of emotional behavior from its influence on motor activity (Franklin \& Tang, 1995; Gendreau et al., 1997b). In recent years, however, there has been a growing interest in the role of DA in mediating emotional behavior. The discovery of the $\mathrm{D}_{3}$ (Sokoloff, Giros, Martres, Bouthenet, \& Schwartz, 1990) and $\mathrm{D}_{4}$ (Van Tol et al., 1991) DA receptor subtypes that are primarily expressed within mesolimbic regions of the brain is manifestly related to this new interest.

As mentioned earlier, our studies showed that DA played a significant role in mediating social-emotional reactivity induced by prolonged social isolation. Following postweaning social isolation, a substantial number of mice display aggressive behavior toward a standard group-housed male. It was demonstrated that systemic injection of a DA agonist was very effective in disorganizing this social pattern and in inducing high levels of fearlike behavior. These effects were not observed in mice that had been reared in social groups (Lewis et al., 1994). Several studies have shown that aggressive behavior can be suppressed by dopaminergic compounds, when the motor system is either clearly overactivated or clearly depressed (Baggio \& Ferrari, 1980; McMillen, DaVanzo, Song, Scott, \& Rodriguez, 1989; Miczek, DeBold, \& van Erp, 1994). Accordingly, the dopaminergic system has been postulated to play a nonspecific, regulatory role on behavior by modifying the level of excitability or arousal (Le Moal \& Simon, 1991). Our results, however, clearly indicated that pharmacological activation of the dopaminergic system induces specific forms of social-emotional reactivity that are independent of the effects on motor activity (see also Franklin \& Tang, 1995). In isolated mice, administration of D2-like DA ligands was shown to depress locomotor activity when testing was conducted in a nonsocial context, but as soon as social interactions were provided, high levels of motor-emotional reactivity reminiscent of fearfulness were commonly observed.

These findings suggest that social deprivation generates its behavioral effects at least partially via alterations in central dopaminergic mechanisms. There are pharmacological and neurochemical studies supporting this hypothesis. Compared to animals that had been reared in social groups, isolated animals have been generally characterized by enhanced sensitivity to the stimulant effects of $d$-amphetamine, apomorphine, or cocaine (Ahmed, Stinus, Le Moal, \& Cador, 1995; Jones et al., 1990; Lewis et al., 1990; Phillips et al., 1994; Wilmot, Vanderwende, \& Spoerlein, 1986). Although some studies did not report this effect (Bowling \& Bardo, 1994; Hall, Fong, Ghaed, \& Pert, 2001; Jones, Hernandez, Kendall, Marsden, \& Robbins, 1992; Weiss, Domeney, Heidbreder, Moreau, \& Feldon, 2001), these observations 
suggest that social deprivation heightens social-emotional reactivity by means of alterations in DA sensitivity. Increased sensitivity to DA was observed in the striatum of rats that had been isolated for 3 months following weaning; then, after 12 months of isolation housing, such hypersensitivity was detected in the cortex (Oehler, Jahkel, \& Schmidt, 1987). In addition, isolated rats was shown to acquire sensitization to amphetamine at a lower dose than that of animals that have been raised in groups; the behavioral response to amphetamine following a stressor (footshock) was also higher in isolated animals (Ahmed et al., 1995). Then, other studies reported no change in DA receptor affinity following prolonged social deprivation (Gariépy et al., 1995, 1998; Rilke, May, Oehler, \& Wolffgramm, 1995; Guisado, Fernandez-Tome, Garzon, \& Del Rio, 1980). Furthermore, no differences in the effects of $\mathrm{D}_{1}\left(\mathrm{SKF}\right.$ 38393) and $\mathrm{D}_{2}$ (quinpirole) DA agonists on cyclic AMP accumulation in the caudate-putamen was found following isolation (Jones et al., 1992). As isolates were more sensitive to the motor depressant effects of a low dose of apomorphine, the authors concluded that isolation primarily alters presynaptic - therefore D2-like receptor - function.

Increased postsynaptic DA receptor density may be another mechanism explaining the enhanced sensitivity of isolated animals to DA agonists. Although $D_{1} / D_{2}$ interactions are required for the expression of a number of behaviors (Waddington \& Daly, 1993), they appear to be differentially malleable by the environment. In comparison with animals that were singly caged, 2-year-old rats that had been exposed to enriched contextual conditions (toys) during 30 days showed an increase in D1-like but not in D2-like receptor density in the striatum (Anderson, Gatley, Rapp, Coburn-Litvak, \& Volkow, 200o). Higher density of striatal D1-like but not D2-like DA receptors was also found in mice following postweaning isolation (Gariépy et al., 1995, 1998). In another study, striatal D2-like receptors were also unaffected by 18 months of social isolation (Rilke, Jahkel, \& Oehler, 1998). One study reported higher levels of D2-like DA binding sites following postweaning isolation housing, but assessment of D1-like receptor was not conducted (Guisado et al., 1980). On the other hand, no differences in D1-like and D2-like DA receptor density were found between isolated animals, group-housed animals, and animals that were raised in a enriched conditions between 30 and 6o days of age (Bardo \& Hammer, 1991). Other studies showed reduced D1-like and D2-like DA receptor density in the striatum and nucleus accumbens of isolated animals (Rilke et al., 1995; Bean \& Lee, 1991). Moreover, the downregulation of D2-like DA receptors was blocked by chronic haloperidol treatment (Bean \& Lee, 1991).

Contrasting results have also been reported concerning activity of the dopaminergic system. Some findings can be interpreted as evidence for lower (re)activity of the mesocorticolimbic DA system, whereas the opposite conclusion can be drawn from other studies. For instance, isolation 
housing has been associated with reduced DA turnover in different brain regions (Weinstock, Speiser, \& Ashkenazi, 1978), with reduced DA turnover after exposure to a stressor (Miura, Qiao, \& Ohta, 2002), and with increased basal level of DA in the nucleus accumbens (Hall et al., 1998; Miura et al., 2002), and prefrontal cortex (Heidbreder et al., 2000; Jones et al., 1992). On the other hand, decreased DOPAC/DA ratio was also found in the cortex of isolated animals, but the reversed pattern was observed in the nucleus accumbens and striatum (Blanc et al., 1980). Higher basal DA turnover was also reported in the amygdala of isolated animals (Heidbreder et al., 2000). In addition, increased DA activity was observed in the nucleus accumbens (Fulford \& Marsden, 1998) and in the frontal cortex of isolated animals (Crespi, Wright, \& Mobius, 1992; Jones et al., 1992). Finally, neurostructural changes in the nigrostriatal DA pathway (Martin, Spicer, Lewis, Gluck, \& Cork, 1991) and reduced levels of tyrosine hydroxylase (a marker for DA neurons) in the striatum (Lewis et al., 1990) have been found following long-term social deprivation in monkeys.

The short- and long-term effects of maternal separation on DA function have also been investigated, albeit less extensively than the effects of postweaning social deprivation. It has been argued that maternal separation alters DA function in a manner opposite to what is observed for postweaning isolation (Hall, 1998). However, similar to the effects of social deprivation later in ontogeny, adult rats that experienced a single 24hour period of maternal separation at postnatal day 3 showed enhanced behavioral response (increased stereotypy) to apomorphine (Rots et al., 1996). In addition, both maternal isolation (Hall et al., 1999; Kehoe, Shoemaker, Arons, Triano, \& Suresh, 1998) and postweaning social deprivation (Jones et al., 1992) were found to increase amphetamine-induced DA release. One study reported that postweaning social deprivation but not maternal deprivation reduced amphetamine-induced sensitization (Weiss et al., 2001). Adult rats that had been maternally separated did not exhibit enhanced behavioral response to amphetamine but showed higher sensitization to the drug after repeated daily injection of saline (Meaney et al., 2002). The effects of maternal separation can be also observed in younger animals. For instance, in 10-day-old rats, 1-hour maternal separation from the second to the ninth day postnatally produced increased DA turnover in hypothalamus and septum whereas nigrostriatal DA activity was reduced (Kehoe et al., 1998). Finally, maternal separation had no effect on $D_{1}$ or $D_{2}$ receptor binding in the prefrontal cortex and nucleus accumbens but substantially decreased DA transporter in caudate/putamen and accumbens (Meaney et al., 2002).

To understand the age-dependent effects of social influences on DA function, it is essential to examine the ontogeny of the dopaminergic system. In rats, density of $\mathrm{D}_{1}, \mathrm{D}_{2}$, and $\mathrm{D}_{4} \mathrm{DA}$ receptors in the caudate-putamen and nucleus accumbens peaks around the fourth postnatal week ( 28 days), 
then declines by about one third to reach adult levels approximately 3 to 4 weeks later (Tarazi, Tomasini, \& Baldessarini, 1998; Tarazi \& Baldessarini, 2000; Teicher, Andersen, \& Hostetter, 1995). Between the first and the fourth week following birth, there is a three- to four-fold increase of DA receptors in these structures (Tarazi and Baldessarinig 1998). A different developmental pattern is observed in the frontal cortex and hippocampus, where DA receptor density increases gradually to reach adult level at about the eighth postnatal week (Tarazi et al., 1998; Tarazi and Baldessarini, 2000). At 25 months of age, D1-like and D2-like DA receptor densities are about 70\% lower than levels observed at 3-4 months of age (Hyttel, 1989; Morelli, Mennini, Cagnotto, Toffano, \& Di Chiara, 1990). In general, DA receptors, at least $\mathrm{D}_{1}$ receptors, are expressed according to a rostral-caudal gradient, with receptors in the more caudal regions being expressed generally prior to those in the more anterior part such as in the frontal cortex (Murrin \& Zeng, 1990). Finally, there are important gender differences in the development of DA function, at least in rats. For instance, male rats have been characterized with greater expression of striatal D1 and D2 than females, but the loss being greater, their adult levels are similar (Andersen, Rutstein, Benzo, Hostetter, \& Teicher, 1997; Andersen \& Teicher, 2000). Gender differences in the ontogeny and expression of DA function is clearly an issue that warrants further examination.

As the development of dopaminergic function shows high levels of variability between structures, genders, and species, it is not surprising that a variety of neurobiological outcomes have been reported following maternal separation or postweaning social deprivation. The differences in the ontogeny of DA function may explain the age-dependent effects of social deprivation on neurobehavioral development. Mapping the normal development of DA function in brain regions associated with the expression of social behavior, particularly those affected by changes in the social environment, is an important step toward understanding the specific and time-dependent effects of social and maternal deprivation on neurobehavioral function.

\section{REVERSIBILITY OF THE EFFECTS OF SOCIAL DEPRIVATION ON SOCIAL BEHAVIOR AND DOPAMINE FUNCTION}

Social deprivation and maternal separation studies have shown that when normal patterns of social interactions are altered during ontogeny, adverse long-term consequences on brain and behavior development often occur. Are these consequences irreversible? Concerning visual, auditory, olfactory, and somatosensory functions, it is well established that their development is somehow conditional to the presence of specific experiential stimulation at definite times during ontogeny (Crair, Gillespie, \& Stryker, 1998; Kral, Hartmann, Tillein, Heid, \& Klinke, 2001; Meisami \& 
Mousavi, 1981; Stern, Maravall, \& Svoboda, 2001). Nevertheless, developmental improvement of these functions is not totally impervious to later environmental influences. In studies of early sensory deprivation during these so-called "critical" periods of development, which produced significant alterations in brain and behavior, functional recovery, albeit at times limited, is indeed achievable (Brainard \& Knudsen, 1998; Cynader, Berman, \& Hein, 1976).

The notion of critical period and the concept of reversibility of brain processes associated with the expression of social behavior are perhaps more controversial. In 1935, Lorenz observed that social bonding or attachment in precocial birds was determined within a very small window of time - "a circumscribed ontogenic phase" (Lorenz, 1981) p. 279 - and that any moving object in proximity would become, for the majority of animals, a sort of permanent "attachment figure." Lorenz, an ethologist with a behaviorist standpoint, argued that the process of imprinting was a simple conditioning response similar to the acquisition of avoidance behavior following a traumatic experience. Furthermore, Lorenz described both conditioning processes as irreversible (Lorenz, 1981). This assumption was not accurate as there is evidence that both imprinting (Salzen \& Meyer, 1967) and avoidance responses (Myslivecek \& Hassmannova, 1979) can be significantly modified by subsequent experience.

The proposition that behavioral patterns are determined during a precise ontogenetic window and do not response to later environmental input is obviously at odds with the notion of plasticity. Although the extent to which a given biological or behavioral feature can be modified is dependent upon the age, genetic-biological predisposition, and prior experience of the individual, malleability of brain and behavior occurs throughout the life span. For that reason, it is perhaps more appropriate, especially when social processes are implied, to refer to sensitive, rather than critical, periods of development. Thus, contrary to the conclusion of Lorenz on the establishment of species identity in birds, social behaviors are not fixed by early experience and irreversible but highly malleable to subsequent social influences provided through education, rehabilitation, therapy, and other societal efforts. Although there are clearly developmental and individual constraints on plasticity, neural reorganization is not limited to the first few years of life. The brain mechanisms involved in the expression of social behavior may be among the most malleable ones - the most open to change, and therefore not limited to early maturation and development. From an evolutionary point of view, such capacity for reorganization throughout ontogeny is clearly favorable (Cairns et al., 1990).

Is there a sensitive period for the establishment of social behavioral patterns? In 1985, Cairns and his colleagues published one of the first systematic studies aimed at determining whether there was a sensitive period for the establishment of social isolation-induced aggression in male 
mice (Cairns et al., 1985). A five by five factorial design that includes five different onsets of isolation (isolation began at postnatal day 21, 28, 35, 56 , or 84 ) and five different durations (no isolation or isolation lasted 1 , $4,16,64$ days) was used. No fewer than 250 experimental animals and 250 test partners were used for this purpose. It was demonstrated that the earlier the onset and longer the duration of isolation housing, the more pronounced were its effects on the expression of aggressive behavior. A similar conclusion was reached in nonhuman primates (Harlow, Dodsworth, \& Harlow, 1965).

Can the effects of social deprivation on behavior be reduced or completely reversed? Again, this depends on the onset and duration of the social deprivation. For instance, monkeys that have been reared in total isolation from birth to 6 months of age and then placed with younger females showed almost complete social-emotional recovery when raised subsequently with younger animals (Suomi \& Harlow, 1972). Return to normal levels of sociability is not as robust when the length of social isolation is prolonged (Harlow \& Suomi, 1971). Comparable findings have been reported for severely deprived Romanian orphans: recovery of cognitive function was complete when adoption occurred prior to 6 months of age, very extensive for children who were adopted before reaching 24 months of age, but more difficult for those who were adopted after that age (O'Connor, Rutter, Beckett, Keaveney, \& Kreppner, 200o). Developmental catch-up was therefore possible for all children, but progress was not as marked when children were placed within a new family home after 2 years of age. These observations in animals and humans indicated that recovery of behavioral and cognitive function is always possible albeit conditional to the age at which transition from adverse to more favorable environmental conditions takes place. Accordingly, "sensitive periods" for the development of normal behavioral patterns can be appreciably extended by providing sufficient environmental enrichment. This rule is also true for the recovery of more basic function such as the development of auditory function (Brainard \& Knudsen, 1998).

Experimental studies in animals and clinical observations in humans indicate that the degree of functional recovery after brain lesion generally correlates negatively with the age at which the lesion has occurred. The greater plasticity of the younger brain compared to the more mature one is known as the "Kennard principle" (Finger \& Wolf, 1988). This principle is not totally accurate, however. For instance, in children functional recovery is better when cortical injury occurs between 12 and 24 months rather than between birth and 12 months of age (Kolb, Gibb, \& Gorny, 2000). Similarly in rats, it was shown that depletion of $D_{1}$ and $D_{2}$ receptors in the striatum following administration of $\mathrm{N}$-ethoxycarbonyl-2ethoxy-1,2-dihydroquinoline (EEDQ) was reversed in 16-day-old animalsand to a lesser degree in 39-day-old animals - but not in 10-day-old pups 
(Crawford, Rowlett, McDougall, \& Bardo, 1994). Also, depletion of striatal DA, which impaired motor function in adults, had no effect in $3^{-}, 15^{-}$, and 20-day-old rat pups. Furthermore, whereas motor recovery was observed within a week when depletion was performed at 27 days of age, recovery took 4 to 5 weeks in older animals (Weihmuller \& Bruno, 1989). A different time course for the upregulation of striatal DA $D_{1}$ and $D_{2}$ receptors following 1-methyl-4-phenyl-1,2,3,6-tetrahydropyridine (MPTP) lesion of the nigrostriatal pathway was also shown, with the upregulation of $D_{1}$ sites being slower but more enduring than that of $\mathrm{D}_{2}$ sites (Weihmuller, Bruno, Neff, \& Hadjiconstantinou, 1990).

There is also evidence that the DA system is highly sensitive to less invasive pharmacological manipulations. For instance, it was shown that two doses $(2 \mathrm{mg})$ of metamphetamine reduced striatal DA transporter binding by $80 \%$ after a week (Harvey, Lacan, Tanious, \& Melega, 2000). Interestingly, improvement was substantial but still incomplete 1.5 years later (a 10\% reduction was still present). These results indicate that the age at which the injury or trauma comes about will determine the nature and intensity of the effects on DA function. The results also demonstrate the considerable malleability of the dopaminergic system in response to severe and milder forms of brain alterations.

As mentioned previously, we observed altered DA receptor density in mice following social isolation (Gariépy et al., 1995). Can these environmentally induced alterations in DA function be overturned? This seems the case, as the effects of 24 days of postweaning social isolation on DA receptor density were fully reversed by regrouping the isolated animals for an additional 24 days (Gariépy et al., 1998). Importantly, this neurobiological recuperation was coupled with a recovery in social behavior, as behavioral patterns returned to normal levels after a period of "rehabilitation." To our knowledge, this is the only evidence showing reversibility of DA function and DA-dependent behavior after an initial period of social deprivation.

\section{CONCLUDING REMARKS ON SOCIAL DEPRIVATION, DOPAMINE FUNCTION, AND SOCIAL DEVELOPMENT}

Studies of the effects of maternal separation and social deprivation on neurobehavioral development have generated a great deal of disparate findings both within and between each experimental model. This is particularly salient at the neurobiological level as contradictory outcomes on a variety of mechanisms have been reported. Based on the evidence reported in this review, however, we can prudently formulate three general statements concerning the effects of social deprivation on DA function: (1) There are variations in social rearing conditions alter the development of the dopaminergic system; (2) these alterations mediate to some 
extent the long-term social-emotional disturbances typically observed following social deprivation; and (3) the effects of social deprivation on DA function are dependent upon the period at which it is initiated and terminated.

Based on the pharmacological data presented earlier, a more specific statement can be put forward: Social deprivation augments the sensitivity to dopamine agonists. What remains ambiguous is the neurochemical mechanism accountable for this supersensitivity as contradictory observations were made. Functional supersensitivity of the dopaminergic system can be produced by denervation, chronic pharmacological blockade, or disuse of DA pathways, an effect that may be mediated by an increase in receptor density (Hess, Albers, Le, \& Creese, 1986; Ungerstedt, Ljungberg, Hoffer, \& Siggins, 1975). Nevertheless, functional supersensitivity can be achieved without an increase in receptor density. For instance, no increase in DA receptor number was observed following bilateral 6-hydroxydopamine lesions of ascending DA pathways (LaHoste \& Marshall, 1992). Also, no increase in D1-like and D2-like receptors or in DA transporters was observed in DA-deficient mice, although these mice showed enhanced behavioral reactivity to D1-like and D2-like DA receptor agonists and to L-DOPA (Kim, Szczypka, \& Palmiter, 2000). Accordingly, many compensatory mechanisms may occur in response to environmental influences that may explicate the enhanced sensitivity of socially deprived animals to dopamine agonists. These mechanisms (i.e., increased receptor density or affinity, enhanced transmitter release, diminished reuptake, sensitized receptors, or other downstream processes) do not appear to be necessary or sufficient to mediate the effects of social deprivation upon behavioral processes.

Assessing the effects of diverse social moderators on the development of specific neurobiological mechanisms is complicated by a host of factors. Discrepancy in biological assays (in vivo, ex vivo, or in vitro) is unlikely to be the main reason for these inconsistencies. Differences in species or strains, and more particularly variation in the time of onset and duration of the social deprivation period, are unambiguous key elements. Apparently, the sensitivity of the organism - its nervous system - to physical and social stimulation varies greatly, with some structures and functions being more susceptible to specific experiences at specific times in ontogeny, and with perhaps more precise and more sensitive windows of susceptibility occuring early in development. For instance, in examining the effects of 24-hr maternal separation on HPA axis responsiveness, it was observed that 20day-old animals deprived at postnatal day 3 were hyperreactive, whereas those separated 8 days later at postnatal day 11 had a blunted HPA axis response (van Oers, De Kloet, \& Levine, 1997). The specific windows of susceptibility for the development of normal DA system and DA-dependent behavior have not been yet established. 
Another critical variable for the contradictory results reported here involves the specific nature of the deprivation. It is already known that the short- and long-term effects of maternal separation on stress response can be prevented by simply stroking the anogenital region of the motherless pups with a fine brush (van Oers, De Kloet, \& Levine, 1999). Similarly, it was shown that levels of licking, grooming, and nursing in an arched-back position are key components of maternal behavior for generating important neural and behavioral alterations in the offspring (Liu, Diorio, Day, Francis, \& Meaney, 2000). These studies indicate the importance of specific physical-social stimulation provided by the mother for normal neurobehavioral development.

Depriving the pups periodically of maternal nursing behavior does not obviously entail the same significance as preventing juveniles or adult animals from interacting socially with same-age conspecifics. What are the animals undergoing postweaning social deprivation deprived of? In rats, neither daily handling nor cohabitation with conspecifics made less active by daily haloperidol treatment were successful in reversing the effects of isolation housing (Bean \& Lee, 1991). In mice, neither daily handling of isolates nor housing one male with females reduced the frequency of intermale fighting (Gariépy, 1995). Although reduced exposure to pheromones may be of significance (Scott, 1966), these results suggest that it is not the amount of tactile stimulation or the passive presence of conspecifics but the level and nature of social interaction that may be the crucial factor for the observed effects. Is the absence of play the critical element as suggested by some authors (Einon, Morgan, \& Kibbler, 1978)? This may be true for rats and perhaps for mice, as they exhibit rudimentary forms of play behavior (Pellis \& Pasztor, 1999) but it is likely that play experience is not the only interactive element missing during prolonged social deprivation (Bekoff, 1976).

A better definition and comprehension of the multiple environmental factors that are manipulated when animals are separated from their mother or deprived from social contact clearly is a necessary step before examining the whole set of brain structures and mechanisms that are associated with the effects of deprivation. As pointed out by Greenough (1988), however: "every change in the environment, no matter how seemingly specific, has nonspecific consequences" (p. 290). With respect to the effects of postweaning social deprivation in mice, heightened aggression may be the specific consequence of not having the opportunity to fight and learn to inhibit aggressive behavior, whereas heightened behavioral reactivity to novelty (not associated with aggressiveness) may be more a matter of lack of social stimulation on the whole. The disruption of prepulse inhibition by social isolation (Robbins, Jones, \& Wilkinson, 1996) may also represent a nonspecific outcome of this experimental procedure. 
It takes time for the brain to mature and show coherent patterns of activity that support adaptive patterns of behavioral organization. In rats, striatal DA efferent neurons reach their target regions only 1 week after birth (Chesselet et al., 2000). Then, maturation of the DA system, as measured by receptor density, is not complete before at least 8 weeks of age (Tarazi et al., 1998). In humans, at least 5 years are necessary before DA receptor density in the striatum gets to adult levels (Seeman et al., 1987). The development of neurobiological functions is thus characterized with discrete qualitative changes during the course of ontogeny. Processes of brain development such as cell production, migration, and differentiation can be influenced by environmental factors during the prenatal and perhaps early postnatal period. Other ontogenetic processes such as myelination and synaptogenesis, that is, the formation of synaptic links between neurons and the regulation of post- and presynaptic receptors or transporters, are open to environmental influences for a much longer period of time, in reality throughout the life span in the case of synaptogenesis (Rice \& Barone, 2000). Functional alterations induced by specific experience (or lack of) may be associated with a reorganization of synaptic circuitry, including increased dendritic arborization, increased spine density, altered receptor density and/or sensitivity, and altered G-protein mechanism.

Much research on brain plasticity has so far focused on the hippocampus and adjacent areas. In recent years, however, increasing evidence indicates that other brain structures - rich in dopaminergic innervations - can be also substantially altered by the environment, even during adulthood. For instance, a high degree of axonal plasticity due to molecular mechanisms different from those occuring in the hippocampus was found in the striatum of adult rats (Chesselet et al., 2000). In addition, long-term potentiation, an important mechanism for synaptic plasticity that persists throughout ontogeny, has been observed in the striatum (Charpier \& Deniau, 1997). There is also evidence that alterations in dopaminergic function may induce structural changes at the level of the synapse. For instance, reduction of dopaminergic activity by administration of $\mathrm{D}_{1}$ and $\mathrm{D}_{2}$ DA antagonists decreased synaptic density in the prefrontal cortex, whereas administration of DA agonist increased it (Sugahara \& Shiraishi, 1998).

It is important to mention that most studies examining the effects of social deprivation or maternal deprivation on brain function have focused on cognitive and/or nonsocial behavior. This may not be surprising, however, as assessment of emotional reactivity in rodents has been traditionally conducted within nonsocial contexts (e.g., open field, elevated plus-maze). Given that the propensity to be "emotional" in a nonsocial context is not necessarily a good predictor of the level of emotional reactivity exhibited in response to social stimulation (Berton, Ramos, Chaouloff, \& Mormede, 
1997; Gariépy, Hood, \& Cairns, 1988; Gendreau et al., 1997a) and given that what isolated animals are deprived of is mainly social interaction, it would be more informative to test the effects of social deprivation on social behavior. Moreover, although it is still common to refer to unitary constructs such as fearfulness, anxiety, fear, depression, and stress without describing the nature of the behavior and the context where it is observed, we believe that it would be beneficial to go beyond the traditional terminology and focus on specific behavior expressed in specific contexts.

All neurobehavioral functions are the result of a complex interaction among genetic, social, and developmental/maturational variables of which it is difficult to control. Animal models afford the unique opportunity of identifying the specific brain structures and neurochemical systems affected by the social environment at specific developmental times. Thanks to the recent advances in molecular biology, pharmacology, and neuroimaging methods, these animal models have provided evidence that alterations in the social environment of the developing organism can induce abnormal behavioral and neurobiological phenotypes, including changes in brain morphology, in neurotransmitter function, and in levels of gene expression. Alteration in dopaminergic function is only one of many processes that can be altered by activity-dependent mechanisms, which are themselves dependent upon the developmental stage of the individual. Although many other neurotransmitter systems (e.g., norepinephrine, serotonin, acetylcholine) have been also shown to be altered by social deprivation, particularly after long-term postweaning social isolation (for a review see Hall, 1998), the DA system appears to be particularly sensitive to environmental influences and to play a very important role in the effects of social deprivation on social-emotional behavior.

Naturally, caution has to be exercised in drawing conclusions based entirely on animal models. The important species differences with respect to social environment and maturation of the neurobiological systems make the interpretation and generalization of the results a very challenging task. Animal models of neurobehavioral development are scientifically relevant when the species-typical effects can be discriminated from those involving more general developmental processes. In this regard, both the maternal separation paradigm and the social deprivation paradigm have contributed to our progress in understanding the general and the specific contribution of social relationships and interactions in the development of neurobehavioral functions.

\section{ACKNOWLEDGMENTS}

Preparation of this chapter was supported by a research grant from the "Fonds pour la Formation de Chercheurs et l'Aide à la Recherche du Québec" to PLG. 


\section{References}

Ahmed, S. H., Stinus, L., Le Moal, M., \& Cador, M. (1995). Social deprivation enhances the vulnerability of male Wistar rats to stressor- and amphetamineinduced behavioral sensitization. Psychopharmacology, 117, 116-124.

Andersen, S. L., Rutstein, M., Benzo, J. M., Hostetter, J. C., \& Teicher, M. H. (1997). Sex differences in dopamine receptor overproduction and elimination. Neuroreport, 8, 1495-1498.

Andersen, S. L., \& Teicher, M. H. (2000). Sex differences in dopamine receptors and their relevance to ADHD. Neuroscience and Biobehavioral Reviews, 24, 137-141.

Anderson, B. J., Gatley, S. J., Rapp, D. N., Coburn-Litvak, P. S., \& Volkow, N. D. (2000). The ratio of striatal Di to muscarinic receptors changes in aging rats housed in an enriched environment. Brain Research, 872, 262-265.

Baggio, G., \& Ferrari, F. (1980). Role of brain dopaminergic mechanisms in rodent aggressive behavior: influence of $(+/-) N-n$-propyl-norapomorphine on three experimental models. Psychopharmacology, 70, 63-68.

Bakwin, H. (1949). Psychologic aspects of pediatrics. Journal of Pediatrics, 35, 512521.

Bardo, M. T., \& Hammer, R. P., Jr. (1991). Autoradiographic localization of dopamine $D_{1}$ and $D_{2}$ receptors in rat nucleus accumbens: resistance to differential rearing conditions. Neuroscience, 45, 281-290.

Bean, G., \& Lee, T. (1991). Social isolation and cohabitation with haloperidol-treated partners: effect on density of striatal dopamine D2 receptors in the developing rat brain. Psychiatry Research, 36, 307-317.

Bekoff, M. (1976). The social deprivation paradigm: who's being deprived of what? Developmental Psychobiology, 9, 499-500.

Bernstein, S., \& Mason, W. A. (1962). The effects of age and stimulus conditions of the emotional responses of Rhesus monkeys: Responses to complex stimuli. Journal of Genetic Psychology, 101, 279-298.

Berton, O., Ramos, A., Chaouloff, F., \& Mormede, P. (1997). Behavioral reactivity to social and nonsocial stimulations: a multivariate analysis of six inbred rat strains. Behavior Genetics, 27, 155-166.

Blanc, G., Herve, D., Simon, H., Lisoprawski, A., Glowinski, J., \& Tassin, J. P. (1980). Response to stress of mesocortico-frontal dopaminergic neurones in rats after long-term isolation. Nature, 284, 265-267.

Blaschko, H. (1957). Metabolism and storage of biogenic amines. Experientia, $13,12$.

Bornstein, M. H. (1989). Sensitive periods in development: structural characteristics and causal interpretations. Psychological Bulletin, 105, 179-197.

Bowlby, J. (1940). The influence of early environment in the development of neurosis and neurotic character. International Journal of Psycho-Analysis, 21, 154-178.

Bowling, S. L., \& Bardo, M. T. (1994). Locomotor and rewarding effects of amphetamine in enriched, social, and isolate reared rats. Pharmacology, Biochemistry and Behavior, 48, 459-464.

Brainard, M. S., \& Knudsen, E. I. (1998). Sensitive periods for visual calibration of the auditory space map in the barn owl optic tectum. Journal of Neuroscience, 18, 3929-3942. 
Cairns, R. B. (1972). Fighting and punishment from a developmental perspective. In J. K. Cole \& D. D. Jensen (Eds.), Nebraska Symposium on motivation (pp. 59-124). Lincoln: University of Nebraska Press.

Cairns, R. B. (1979). Social development: the origins and plasticity of interchanges. San Franscisco: Freeman.

Cairns, R. B., Gariépy, J. L., \& Hood, K. E. (1990). Development, microevolution, and social behavior. Psychological Review, 97, 49-65.

Cairns, R. B., Hood, K. E., \& Midlam, J. (1985). On fighting in mice: is there a sensitive period for isolation effects? Animal Behavior, 33, 166-180.

Cairns, R. B., MacCombie, D. J., \& Hood, K. E. (1983). A developmental-genetic analysis of aggressive behavior in mice: I. Behavioral outcomes. Journal of Comparative Psychology, 97, 69-89.

Carlsson, A., Lindqvist, M., Magnusson, T., \& Waldeck, B. (1958). On the presence of 3-hydroxytyramine in brain. Science, 127, 471.

Carmichael, L. (1925). Heredity and environment: are they antithetical? Journal of Abnormal and Social Psychology, 20, 245-260.

Charpier, S., \& Deniau, J. M. (1997). In vivo activity-dependent plasticity at corticostriatal connections: Evidence for physiological long-term potentiation. Proceedings of the National Academy of Sciences, USA, 94, 7036-7040.

Chesselet, M. F., Butler, A. K., Napieralski, J. A., Morehouse, W. V., Szele, F. G., \& Uryu, K. (2000). Anatomical plasticity in the striatum during development and after lesions in the adult rat. In M. Baudry, J. L. Davis, \& R. F. Thompson (Eds.), Advances in synaptic plasticity (pp. 167-195). Cambridge, MA: The MIT Press.

Craig, W. (1914). Males doves reared in isolation. Journal of Animal Behavior, 4, 121133.

Crair, M. C., Gillespie, D. C., \& Stryker, M. P. (1998). The role of visual experience in the development of columns in cat visual cortex. Science, 279, 566-570.

Crawford, C. A., Rowlett, J. K., McDougall, S. A., \& Bardo, M. T. (1994). Agedependent differences in the rate of recovery of striatal dopamine D1 and D2 receptors after inactivation with EEDQ. European Journal of Pharmacology, 252, $225-231$.

Crespi, F., Wright, I. K., \& Mobius, C. (1992). Isolation rearing of rats alters release of 5-hydroxytryptamine and dopamine in the frontal cortex: An in vivo electrochemical study. Experimental Brain Research, 88, 495-501.

Cynader, M., Berman, N., \& Hein, A. (1976). Recovery of function in cat visual cortex following prolonged deprivation. Experimental Brain Research, 25, 139-156.

Diamond, M. C., Krech, D., \& Rozenzweig, M. R. (1964). The effects of an enriched environment on the histology of the rat cerebral cortex. Journal of Comparative Neurology, 123, 111-120.

Einon, D. F., Morgan, M. J., \& Kibbler, C. C. (1978). Brief periods of socialization and later behavior in the rat. Developmental Psychobiology, 11, 213-225.

Finger, S., \& Wolf, C. (1988). The 'Kennard effect' before Kennard. The early history of age and brain lesions. Archives of Neurology, 45, 1136-1142.

Foley, J. P. (1934). First year development of a rhesus monkey (Macaca mulatta) reared in isolation. Journal of Genetic Psychology, 45, 39-105.

Franklin, S. R., \& Tang, A. H. (1995). Dopamine agonists facilitate footshock-elicited locomotion in rats, and suppress level-press responding for food. Psychopharmacology, 121, 480-484. 
Fulford, A. J., \& Marsden, C. A. (1998). Effect of isolation-rearing on conditioned dopamine release in vivo in the nucleus accumbens of the rat. Journal of Neurochemistry, 70, 384-390.

Fuller, J. L., \& Clark, L. D. (1966). Genetic and treatment factors modifying the postisolation syndrome in dogs. Journal of Comparative and Physiological Psychology, 61, 251-257.

Gariépy, J.-L. (1995). The mediation of aggressive behavior in mice: a discussion of approach/withdrawal processes in social adaptations. In K. E. Hood, G. Greenberg, \& E. Tobach (Eds.), Behavioral development: Concepts of approach/ withdrawal and integrative levels (pp. 231-285). New York: Garland Publishing.

Gariépy, J. L., Gendreau, P. L., Cairns, R. B., \& Lewis, M. H. (1998). D1 dopamine receptors and the reversal of isolation-induced behaviors in mice. Behavioural Brain Research, 95, 103-111.

Gariépy, J. L., Gendreau, P. L., Mailman, R. B., Tancer, M., \& Lewis, M. H. (1995). Rearing conditions alter social reactivity and Di dopamine receptors in high- and low-aggressive mice. Pharmacology, Biochemistry and Behavior, 51, 767-773.

Gariépy, J. L., Hood, K. E., \& Cairns, R. B. (1988). A developmental-genetic analysis of aggressive behavior in mice (Mus musculus): III. Behavioral mediation by heightened reactivity or immobility? Journal of Comparative Psychology, 102, 392-399.

Gariépy, J.-L., Lewis, M. H., \& Cairns, R. B. (1996). Genes, neurobiology, and aggression: Time frames and functions of social behaviors in adaptation. In $\mathrm{M}$. Stoff \& R. B. Cairns (Eds.), Aggression and violence: Neurobiological, biosocial and genetic perspectives (pp. 41-63). New York: Lawrence Erlbaum.

Gendreau, P. L., Gariépy, J. L., Petitto, J. M., \& Lewis, M. H. (1997a). D1 dopamine receptor mediation of social and nonsocial emotional reactivity in mice: Effects of housing and strain difference in motor activity. Behavioral Neuroscience, 111, 424-434.

Gendreau, P. L., Petitto, J. M., Gariépy, J. L., \& Lewis, M. H. (1998). D2-like dopamine receptor mediation of social-emotional reactivity in a mouse model of anxiety: Strain and experience effects. Neuropsychopharmacology, 18, 210-221.

Gendreau, P. L., Petitto, J. M., Petrova, A., Gariépy, J., \& Lewis, M. H. (2000). $\mathrm{D}(3)$ and $\mathrm{D}(2)$ dopamine receptor agonists differentially modulate isolationinduced social-emotional reactivity in mice. Behavioural Brain Research, 114, 107-117.

Gendreau, P. L., Petitto, J. M., Schnauss, R., Frantz, K. J., Van Hartesveldt, C., Gariépy, J. L., et al. (1997b). Effects of the putative dopamine D3 receptor antagonist PNU 99194A on motor behavior and emotional reactivity in C57BL/6J mice. European Journal of Pharmacology, 337, 147-155.

Gluck, J. P., \& Sackett, G. P. (1974). Frustration and self-aggression in social isolate rhesus monkeys. Journal of Adolescence, 83, 331-334.

Goosen, C. (1981). Abnormal behavior patterns in rhesus monkeys: Symptoms of mental disease. Biological Psychiatry, 16, 697-716.

Greenough, W. T. (1988). The turned-on brain: Developmental and adult responses to the demands of information storage. In S. C.Easter, K. F. Barald, \& B. M. Carlson (Eds.), From message to mind: Directions in developmental neurobiology (pp. 288-302). Sunderland, MA: Sinauer Associates. 
Greenough, W. T., Black, J. E., \& Wallace, C. S. (1987). Experience and brain development. Child Development, 58, 539-559.

Guisado, E., Fernandez-Tome, P., Garzon, J., \& Del Rio, J. (1980). Increased dopamine receptor binding in the striatum of rats after long- term isolation. European Journal of Pharmacology, 65, 463-464.

Hall, F. S. (1998). Social deprivation of neonatal, adolescent, and adult rats has distinct neurochemical and behavioral consequences. Critical Review in Neurobiology, $12,129-162$.

Hall, F. S., Fong, G. W., Ghaed, S., \& Pert, A. (2001). Locomotor-stimulating effects of indirect dopamine agonists are attenuated in Fawn hooded rats independent of postweaning social experience. Pharmacology, Biochemistry and Behavior, 69, 519-526.

Hall, F. S., Wilkinson, L. S., Humby, T., Inglis, W., Kendall, D. A., Marsden, C. A. et al. (1998). Isolation rearing in rats: Pre- and postsynaptic changes in striatal dopaminergic systems. Pharmacology, Biochemistry and Behavior, 59, 859-872.

Hall, F. S., Wilkinson, L.S., Humby, T., \& Robbins, T. W. (1999). Maternal deprivation of neonatal rats produces enduring changes in dopamine function. Synapse, 32 , $37-43$.

Harlow, H. F., Dodsworth, R. O., \& Harlow, M. K. (1965). Total social isolation in monkeys. Proceedings of the National Academy of Sciences, USA, 54, 90-97.

Harlow, H. F., \& Suomi, S. J. (1971). Social recovery by isolation-reared monkeys. Proceedings of the National Academy of Sciences, USA, 68, 1534-1538.

Harlow, H. F., \& Suomi, S. J. (1974). Induced depression in monkeys. Behavioral Biology, 12, 273-296.

Harvey, D. C., Lacan, G., Tanious, S. P., \& Melega, W. P. (2000). Recovery from methamphetamine induced long-term nigrostriatal dopaminergic deficits without substantia nigra cell loss. Brain Research, 871, 259-270.

Hatch, A. M., Wiberg, G. S., Zawidzka, Z., Cann, M., Airth, J. M., \& Grice, H. C. (1965). Isolation syndrome in the rat. Toxicology and Applied Pharmacology, 7, 737745 .

Heidbreder, C. A., Weiss, I. C., Domeney, A. M., Pryce, C., Homberg, J., Hedou, G., et al. (2000). Behavioral, neurochemical and endocrinological characterization of the early social isolation syndrome. Neuroscience, 100, 749-768.

Hess, E. J., Albers, L. J., Le, H., \& Creese, I. (1986). Effects of chronic SCH23390 treatment on the biochemical and behavioral properties of D1 and D2 dopamine receptors: Potentiated behavioral responses to a D2 dopamine agonist after selective Di dopamine receptor upregulation. Journal of Pharmacology and Experimental Therapeutics, 238, 846-854.

Hinde, R. A., \& Spencer-Booth, Y. (1971). Effects of brief separation from mother on rhesus monkeys. Science, 173, 111-118.

Hofer, M. A. (1975). Survival and recovery of physiologic functions after early maternal separation in rats. Physiology and Behavior, 15, 475-480.

Hubel, D. H., \& Wiesel, T. N. (1970). The period of susceptibility to the physiological effects of unilateral eye closure in kittens. Journal of Physiology, 206, 419-436.

Hyttel, J. (1989). Parallel decrease in the density of dopamine D1 and D2 receptors in corpus striatum of rats from 3 to 25 months of age. Pharmacology and Toxicology, $64,55-57$. 
James, W. (1892). In G. Allport (Ed.), Psychology: The briefer course. New York: Harper \& Brothers.

Jones, G. H., Hernandez, T. D., Kendall, D. A., Marsden, C. A., \& Robbins, T. W. (1992). Dopaminergic and serotonergic function following isolation rearing in rats: Study of behavioural responses and postmortem and in vivo neurochemistry. Pharmacology, Biochemistry and Behavior, 43, 17-35.

Jones, G. H., Marsden, C. A., \& Robbins, T. W. (1990). Increased sensitivity to amphetamine and reward-related stimuli following social isolation in rats: Possible disruption of dopamine-dependent mechanisms of the nucleus accumbens. Psychopharmacology, 102, 364-372.

Kaufman, I. C., \& Rosenblum, L. A. (1967). Depression in infant monkeys separated from their mothers. Science, 155, 1030-1031.

Kehoe, P., Shoemaker, W. J., Arons, C., Triano, L., \& Suresh, G. (1998). Repeated isolation stress in the neonatal rat: Relation to brain dopamine systems in the 10-day-old rat. Behavioral Neuroscience, 112, 1466-1474.

Kim, D. S., Szczypka, M. S., \& Palmiter, R. D. (2000). Dopamine-deficient mice are hypersensitive to dopamine receptor agonists. Journal of Neuroscience, 20, 44054413.

Kolb, B., Gibb, R., \& Gorny, G. (2000). Cortical plasticity and the development of behavior after early frontal cortical injury. Developmental Neuropsychology, 18, 423-444.

Kral, A., Hartmann, R., Tillein, J., Heid, S., \& Klinke, R. (2001). Delayed maturation and sensitive periods in the auditory cortex. Audiology and Neurootology, 6, 346362.

Krech, D., Rozenzweig, M. R., \& Bennett, E. L. (1960). Effects of environmental complexity and training on brain chemistry. Journal of Comparative Physiology and Psychology, 53, 509-519.

Krsiak, M. (1975). Timid singly-housed mice: Their value in prediction of psychotropic activity of drugs. British Journal of Pharmacology, 55, 141-150.

Lagerspetz, K. Y., Tirri, R., \& Lagerspetz, K. M. (1968). Neurochemical and endocrinological studies of mice selectively bred for aggressiveness. Scandinavian Journal of Psychology, 9, 157-160.

LaHoste, G. J., \& Marshall, J. F. (1992). Dopamine supersensitivity and D1/D2 synergism are unrelated to changes in striatal receptor density. Synapse, 12, 1426.

Le Moal, M., \& Simon, H. (1991). Mesocorticolimbic dopaminergic network: functional and regulatory roles. Physiological Reviews, 71, 155-234.

Lewis, M. H., Gariépy, J. L., Gendreau, P. L., Nichols, D. E., \& Mailman, R. B. (1994). Social reactivity and Di dopamine receptors: Studies in mice selectively bred for high and low levels of aggression. Neuropsychopharmacology, 10, $115-122$.

Lewis, M. H., Gluck, J. P., Beauchamp, A. J., Keresztury, M. F., \& Mailman, R. B. (1990). Long-term effects of early social isolation in Macaca mulatta: Changes in dopamine receptor function following apomorphine challenge. Brain Research, $513,67-73$.

Liu, D., Diorio, J., Day, J. C., Francis, D. D., \& Meaney, M. J. (200o). Maternal care, hippocampal synaptogenesis and cognitive development in rats. Nature Neuroscience, 3, 799-806. 
Lorenz, K. (1981). The foundations of ethology. New York: Simon and Schuster.

Martin, L. J., Spicer, D. M., Lewis, M. H., Gluck, J. P., \& Cork, L. C. (1991). Social deprivation of infant rhesus monkeys alters the chemoarchitecture of the brain: I. Subcortical regions. Journal of Neuroscience, 11, 3344-3358.

Mason, W. A., \& Berkson, G. (1975). Effects of maternal mobility on the development of rocking and other behaviors in rhesus monkeys: a study with artificial mothers. Developmental Psychobiology, 8, 197-211.

Mason, W. A., \& Sponholz, R. R. (1963). Behavior of rhesus monkeys raised in isolation. Journal of Psychiatric Research, 1, 299-306.

Matthews, K., Dalley, J. W., Matthews, C., Tsai, T. H., \& Robbins, T. W. (2001). Periodic maternal separation of neonatal rats produces region- and genderspecific effects on biogenic amine content in postmortem adult brain. Synapse, 40, 1-10.

McCulloch, T. L., \& Haselrud, G. M. (1939). Development of an infant chimpanzee during her first year. Journal of Comparative Psychology, 28, 437-445.

McMillen, B. A., DaVanzo, E. A., Song, A. H., Scott, S. M., \& Rodriguez, M. E. (1989). Effects of classical and atypical antipsychotic drugs on isolationinduced aggression in male mice. European Journal of Pharmacology, 160, 149-153.

Meaney, M. J., Brake, W., \& Gratton, A. (2002). Environmental regulation of the development of mesolimbic dopamine systems: A neurobiological mechanism for vulnerability to drug abuse? Psychoneuroendocrinology, 27, 127-138.

Meisami, E., \& Mousavi, R. (1981). Lasting effects of early olfactory deprivation on the growth, DNA, RNA and protein content, and Na-K-ATPase and AchE activity of the rat olfactory bulb. Brain Research, 254, 217-229.

Miczek, K. A., DeBold, J. F., \& van Erp, A. M. (1994). Neuropharmacological characteristics of individual differences in alcohol effects on aggression in rodents and primates. Behavioral Pharmacology, 5, 407-421.

Miura, H., Qiao, H., \& Ohta, T. (2002). Attenuating effects of the isolated rearing condition on increased brain serotonin and dopamine turnover elicited by novelty stress. Brain Research, 926, 10-17.

Morelli, M., Mennini, T., Cagnotto, A., Toffano, G., \& Di Chiara, G. (1990). Quantitative autoradiographical analysis of the age-related modulation of central dopamine D1 and D2 receptors. Neuroscience, 36, 403-410.

Murrin, L. C., \& Zeng, W. Y. (1990). Ontogeny of dopamine Di receptors in rat forebrain: A quantitative autoradiographic study. Brain Research. Developmental Brain Research, 57, 7-13.

Myslivecek, J., \& Hassmannova, J. (1979). Ontogeny of active avoidance in the rat: Learning and memory. Developmental Psychobiology, 12, 169-186.

O'Connor, T. G., Rutter, M., Beckett, C., Keaveney, L., \& Kreppner, J. M. (2000). The effects of global severe privation on cognitive competence: Extension and longitudinal follow-up. English and Romanian Adoptees Study Team. Child Development, 71, 376-390.

Oehler, J., Jahkel, M., \& Schmidt, J. (1987). Neuronal transmitter sensitivity after social isolation in rats. Physiology and Behavior, 41, 187-191.

Pellis, S. M., \& Pasztor, T. J. (1999). The developmental onset of a rudimentary form of play fighting in $\mathrm{C}_{57}$ mice. Developmental Psychobiology, 34, $175-182$. 
Phillips, G. D., Howes, S. R., Whitelaw, R. B., Wilkinson, L. S., Robbins, T. W., \& Everitt, B. J. (1994). Isolation rearing enhances the locomotor response to cocaine and a novel environment, but impairs the intravenous self-administration of cocaine. Psychopharmacology, 115, 407-418.

Rice, D., \& Barone S Jr (2000). Critical periods of vulnerability for the developing nervous system: Evidence from humans and animal models. Environmental Health Perspectives, 108 (Suppl 3), 511-533.

Rilke, O., Jahkel, M., \& Oehler, J. (1998). Dopaminergic parameters during social isolation in low- and high-active mice. Pharmacology, Biochemistry and Behavior, $60,499-505$.

Rilke, O., May, T., Oehler, J., \& Wolffgramm, J. (1995). Influences of housing conditions and ethanol intake on binding characteristics of D2, 5-HT1A, and benzodiazepine receptors of rats. Pharmacology, Biochemistry and Behavior, 52, 23-28.

Robbins, T. W., Jones, G. H., \& Wilkinson, L. S. (1996). Behavioural and neurochemical effects of early social deprivation in the rat. Journal of Psychopharmacology, 10, 39-47.

Rodgers, R. J., \& Cole, J. C. (1993). Influence of social isolation, gender, strain, and prior novelty on plus-maze behaviour in mice. Physiology and Behavior, 54, 729-736.

Rots, N. Y., de Jong, J., Workel, J. O., Levine, S., Cools, A. R., \& De Kloet, E. R. (1996). Neonatal maternally deprived rats have as adults elevated basal pituitaryadrenal activity and enhanced susceptibility to apomorphine. Journal of Neuroendocrinology, 8, 501-506.

Rozenzweig, M. R., Krech, D., Bennett, E. L., \& Diamond, M. C. (1962). Effects of enviromental compexity and training on brain chemistry and anatomy. Journal of Comparative Physiology and Psychology, 55, 429-437.

Salzen, E. A., \& Meyer, C. C. (1967). Imprinting: Reversal of a preference established during the critical period. Nature, 215, 785-786.

Sanchez, M. M., Ladd, C. O., \& Plotsky, P. M. (2001). Early adverse experience as a developmental risk factor for later psychopathology: Evidence from rodent and primate models. Development and Psychopathology, 13, 419-449.

Scott, J. P. (1966). Agonistic behavior of mice and rats: a review. American Zoology, 6, 683-701.

Seeman, P., Bzowej, N. H., Guan, H. C., Bergeron, C., Becker, L. E., Reynolds, G. P., et al. (1987). Human brain dopamine receptors in children and aging adults. Synapse, 1, 399-404.

Sokoloff, P., Giros, B., Martres, M. P., Bouthenet, M. L., \& Schwartz, J. C. (1990). Molecular cloning and characterization of a novel dopamine receptor $\left(D_{3}\right)$ as a target for neuroleptics. Nature, 347, 146-151.

Spitz, R. A., (1945). Hospitalism: An inquiry into the genesis of Psychiatric conditions in early childhood. Psychoanalytic Study of the Child, 1, 53-74.

Spitz, R. A., \& Wolf, K. M. (1946). Anaclitic depression: An inquiry into the genesis of psychiatric conditions in early childhood, II. Psychoanalytic Study of the Child, $2,313-342$.

Stern, E. A., Maravall, M., \& Svoboda, K. (2001). Rapid development and plasticity of layer 2/3 maps in rat barrel cortex in vivo. Neuron, 31, 305-315. 
Stone, C. P. (1926). The initial copulatory response of female rats reared in isolation from the age of 20 days to age of puberty. Journal of Comparative Psychology, 6, $78-83$.

Sugahara, M., \& Shiraishi, H. (1998). Synaptic density of the prefrontal cortex regulated by dopamine instead of serotonin in rats. Brain Research, 814, 143-156.

Suomi, S. J., \& Harlow, H. F. (1972). Social rehabilitation of isolate-reared monkeys. Developmental Psychology, 6, 487-496.

Tancer, M. E, Gariépy, J.-L., Mayleben, M. A., Petitto, J. M., \& Lewis, M. H. (1992). NC10o mice: A putative animal model for social phobia. Washington, DC: Society of Biological Psychiatry.

Tarazi, F. I., \& Baldessarini, R. J. (2000). Comparative postnatal development of dopamine $\mathrm{D}(1), \mathrm{D}(2)$ and $\mathrm{D}(4)$ receptors in rat forebrain. International Journal of Developmental Neuroscience, 18, 29-37.

Tarazi, F. I., Tomasini, E. C., \& Baldessarini, R. J. (1998). Postnatal development of dopamine $\mathrm{D}_{4}$-like receptors in rat forebrain regions: Comparison with D2-like receptors. Brain Research. Developmental Brain Research, 110, 227-233.

Teicher, M. H., Andersen, S. L., \& Hostetter, J. C., Jr. (1995). Evidence for dopamine receptor pruning between adolescence and adulthood in striatum but not nucleus accumbens. Brain Research. Developmental Brain Research, 89, 167-172.

Ungerstedt, U., Ljungberg, T., Hoffer, B., \& Siggins, G. (1975). Dopaminergic supersensitivity in the striatum. Advances in Neurology, 9, 57-65.

Valzelli, L. (1973). The "isolation syndrome" in mice. Psychopharmacologia, 31, 305320.

van Oers, H. J., De Kloet, E. R., \& Levine, S. (1997). Persistent, but paradoxical, effects on HPA regulation of infants maternally deprived at different ages. Stress, $1,249-262$.

van Oers, H. J., De Kloet, E. R., \& Levine, S. (1999). Persistent effects of maternal deprivation on HPA regulation can be reversed by feeding and stroking, but not by dexamethasone. Journal of Neuroendocrinology, 11, 581-588.

Van Tol, H. H., Bunzow, J. R., Guan, H. C., Sunahara, R. K., Seeman, P., Niznik, H. B., et al. (1991). Cloning of the gene for a human dopamine $\mathrm{D}_{4}$ receptor with high affinity for the antipsychotic clozapine. Nature, 350, 610-614.

Waddington, J. L., \& Daly, S. A. (1993). Regulation of unconditioned motor behaviour by D1:D2 interactions. In J. L.Waddington (Ed.), D1:D2 dopamine receptor interactions (pp. 51-78). San Diego: Academic Press.

Weihmuller, F. B., \& Bruno, J. P. (1989). Age-dependent plasticity in the dopaminergic control of sensorimotor development. Behavioural Brain Research, 35, 95-109.

Weihmuller, F. B., Bruno, J. P., Neff, N. H., \& Hadjiconstantinou, M. (1990). Dopamine receptor plasticity following MPTP-induced nigrostriatal lesions in the mouse. European Journal of Pharmacology, 180, 369-372.

Weinstock, M., Speiser, Z., \& Ashkenazi, R. (1978). Changes in brain catecholamine turnover and receptor sensitivity induced by social deprivation in rats. Psychopharmacology, 56, 205-209.

Weiss, I. C., Domeney, A. M., Heidbreder, C. A., Moreau, J. L., \& Feldon, J. (2001). Early social isolation, but not maternal separation, affects behavioral sensitization to amphetamine in male and female adult rats. Pharmacology, Biochemistry and Behavior, 70, 397-409. 
Wiesel, T. N., \& Hubel, D. H. (1965). Comparison of the effects of unilateral and bilateral eye closure on cortical unit responses in kittens. Journal of Neuroscience, 28, 1029-1040.

Wilmot, C. A., Vanderwende, C., \& Spoerlein, M. T. (1986). Behavioral and biochemical studies of dopamine receptor sensitivity in differentially housed mice. Psychopharmacology, 89, 364-369. 